\title{
HIDRÓLISE ENZIMÁTICA DE PECTINA PARA A PRODUÇÃO DE POLIHIDROXIALCANOATOS POR Cupriavidus necator
}

\author{
G.O. LOCATELLI, L. FINKLER e C. L. L. FINKLER \\ Universidade Federal de Pernambuco, Centro Acadêmico de Vitória. \\ E-mail para contato: gabriel_locatelli@hotmail.com
}

\begin{abstract}
RESUMO - Resíduos agroindustriais, provenientes da extração de sucos de frutas cítricas, são ricas fontes de substâncias pécticas. Objetivando o aproveitamento desses resíduos como uma alternativa de baixo custo para a produção de biopolímeros, foi estudado o uso de hidrolisados pécticos para crescimento celular e produção de polihidroxialcanoatos por Cupriavidus necator. Nesse trabalho foi empregada uma pectina cítrica comercial $\left(\operatorname{Vetec}^{\circledR}\right)$ e uma endo-poligalacturonase $\left(\right.$ Sigma $\left.{ }^{\circledR}\right)$, sendo realizado um estudo das condições de hidrólise que favorecessem a obtenção de compostos redutores (CR) por meio da aplicação de planejamento fatorial e metodologia de superfície de resposta. As variáveis investigadas foram a concentração de enzima e a agitação, mantendo-se a concentração de substrato em $1 \%(\mathrm{p} / \mathrm{v})$. Os resultados obtidos foram comparados com a performance enzimática realizada a uma maior concentração de substrato $(10 \% \mathrm{p} / \mathrm{v})$ empregando-se diferentes concentrações de enzima. Ambos os resultados indicaram que a concentração enzimática de $10 \mathrm{UI} / \mathrm{g}$ de pectina favoreceu a obtenção de $\mathrm{CR}$, permitindo atingir em média $70 \mathrm{~g} / \mathrm{L}$ de $\mathrm{CR}$ a partir de $100 \mathrm{~g} / \mathrm{L}$ de pectina. O meio de cultura formulado a partir desse hidrolisado foi satisfatório para o crescimento celular de $C$. necator, sendo obtida uma concentração de células acima de $10 \mathrm{~g} / \mathrm{L}$ e o acúmulo intracelular de polihidroxialcanoatos.
\end{abstract}

\section{INTRODUÇÃO}

O Brasil é um dos lideres mundiais na produção de laranja e maracujá, sendo a maior parte destinada à industrialização e gerando grandes volumes de resíduos. A pectina representa a maior parte desse material, atingindo em torno de $50 \%$ do peso dos frutos. A pectina é um heteropolímero com alto peso molecular, contendo majoritariamente (em torno de 65\%) unidades de ácido galacturônico (MAY, 2000), além de outros açúcares neutros em diferentes proporções, como ramnose, galactose, arabinose e xilose (YAPO et al., 2006). Pode ser degradada por métodos de hidrólise ácida ou enzimática, levando a formação de compostos redutores $(\mathrm{CR})$, mas poucos trabalhos têm sido feitos visando à sacarificação da pectina. $\mathrm{O}$ ácido $\mathrm{D}$-galacturônico é uma importante matéria-prima na indústria de alimentos, farmacêutica e de cosméticos e apresenta grande potencial para ser utilizado como substrato em processos de conversão biológica, como a produção de polihidroxialcanoatos (PHA's).

Os PHA's são poliésteres de ácidos carboxílicos, acumulados como material de reserva energética por mais de uma centena de espécies de micro-organismos. Suas propriedades mecânicas têm atraído a atenção como uma alternativa biodegradável para substituir os 
plásticos de origem petroquímica. No entanto, a produção desses biopolímeros ainda chega a ser de 5 a 10 vezes mais dispendiosa do que os polímeros de síntese química (POIRIER et al., 1995). Diversos substratos já foram testados como fonte de carbono para crescimento celular e produção de PHA's por $C$. necator, entre eles: galactose, hidrolisado de lactose, açúcar invertido, melaço cítrico, melaço de cana-de-açúcar, diversos óleos vegetais e ácido acrílico.

A industrialização de frutas cítricas gera grandes volumes de resíduos sólidos e líquidos. O melaço cítrico, despejo líquido com alta concentração de açúcares e ácidos orgânicos, já é descrito como fonte promissora para a produção de PHA's por C. necator (FARIAS, 2009). Mas não foram encontrados na literatura trabalhos que relatem o emprego dos resíduos sólidos ou os produtos de hidrólise da pectina para a produção de PHA's por $C$. necator. Trabalhos anteriores do grupo demonstraram a capacidade de crescimento celular de $C$. necator utilizando ácido galacturônico e hidrolisados pécticos como única fonte de carbono (LOCATELLI et al., 2011, LOCATELLI, 2012). Desta forma, o objetivo deste trabalho foi investigar as condições de hidrólise enzimática da pectina que favorecessem a obtenção de CR por meio da aplicação de planejamento fatorial e metodologia de superfície de resposta e utilizar esse substrato na formulação de meio de cultura para crescimento celular e produção de PHA's por $C$. necator.

\section{MATERIAIS E MÉTODOS}

Os ensaios de hidrólise foram realizados utilizando como substrato uma pectina cítrica comercial $\left(\operatorname{Vetec}^{\circledR}\right)$ de alto grau de esterificação $(67 \%)$. A enzima endo-poligalacturonase utilizada foi adquirida da Sigma ${ }^{\circledR}$, classificada de acordo com "Enzyme Comission" (EC) como E.C. 3.2.1.15, com atividade enzimática de 1,32 UI por mg de enzima, onde 1 UI (Unidade de atividade enzimática) é a quantidade de enzima capaz de liberar $1 \mu$ mol de ácido galacturônico por minuto.

\subsection{Hidrólise Enzimática}

As condições ótimas para a atividade enzimática da enzima E.C 3.2.1.15 são: $\mathrm{pH}$ 4,0 e temperatura de $50^{\circ} \mathrm{C}$, parâmetros esses estabelecidos pela Sigma ${ }^{\circledR}$. Ensaios preliminares indicaram que a enzima tem boa atividade sobre a forma comercial da pectina, com alto grau de esterificação, e que as variáveis concentração de enzima e agitação têm influência direta sobre a variável resposta concentração de CR (LOCATELLI et al., 2011).

Desta forma, elaborou-se um planejamento fatorial completo $2^{2}$, com três pontos centrais (nível 0) e quatro axiais (níveis $\pm \alpha$, onde $\alpha=1,4142$ ), totalizando 11 ensaios (Planejamento Composto Central Rotacional - PCCR, Tabela 1). As variáveis estudadas foram a concentração de enzima e a agitação, mantendo-se constante a concentração de substrato (pectina) em $1 \%(\mathrm{p} / \mathrm{v})$ e tendo como variável resposta a concentração final de CR. Os ensaios foram realizados em frascos Erlenmeyer de $125 \mathrm{~mL}$ contendo $50 \mathrm{~mL}$ de tampão acetato de sódio ( $\mathrm{pH} 4,0,50 \mathrm{mM}$ ) e $0,5 \mathrm{~g}$ de pectina, incubados a $50{ }^{\circ} \mathrm{C}$ por 24 horas em mesa incubadora agitadora $\left(\right.$ Marconi $^{\circledR}$ ). Baseado no planejamento fatorial foi possível definir uma condição ótima entre as variáveis estudadas que favoreceram a obtenção de CR. 
Tabela 1 - Níveis codificados e valores reais das variáveis estudadas para o planejamento experimental nos ensaios de hidrólise enzimática.

\begin{tabular}{ccc}
\hline Ensaios & Conc. Enzima (UI/g) & Agitação (rpm) \\
\hline 1 & $6,9(-1)$ & $211,6(-1)$ \\
2 & $11,1(+1)$ & $211,6(-1)$ \\
3 & $6,9(-1)$ & $268,4(+1)$ \\
4 & $11,1(+1)$ & $268,4(+1)$ \\
5 & $6,0(-1,41)$ & $240(0)$ \\
6 & $12,0(+1,41)$ & $240(0)$ \\
7 & $9,0(0)$ & $200(-1,41)$ \\
8 & $9,0(0)$ & $280(+1,41)$ \\
9 & $9,0(0)$ & $240(0)$ \\
10 & $9,0(0)$ & $240(0)$ \\
11 & $9,0(0)$ & $240(0)$ \\
\hline
\end{tabular}

Considerando a necessidade de se trabalhar com concentrações mais elevadas de substrato para a produção de PHA's, os resultados do planejamento fatorial foram comparados com a performance enzimática, realizada com uma maior concentração de substrato $(10 \% \mathrm{p} / \mathrm{v})$ empregando-se diferentes concentrações de enzima. Nessas condições, resultados anteriores demonstraram que a agitação tem grande influência na hidrólise, pois promove um maior contato da enzima com o substrato, sendo empregado o nível máximo de agitação (300 rpm) (LOCATELLI, 2012).

Em sistemas heterogêneos, onde há altas concentrações de substrato sólido e quando altas concentrações de enzima são usadas, ocorre a saturação dos sítios exteriores dos substratos com a enzima, sem acarretar em grandes incrementos nas taxas de biotransformação. Nesses sistemas industriais as curvas clássicas de Michaelis-Menten não se aplicam. Para a otimização dos processos de biocatálise industrial, a concentração ideal de enzima pode ser medida pela performance da mesma sobre o seu substrato, onde uma redução efetiva na dosagem enzimática pode representar pouco efeito sobre o seu desempenho (CAVACO-PAULO, 2011). Desta forma, foi realizado um ensaio de performance enzimática mantendo-se a agitação máxima de 300 rpm e a concentração de substrato em $10 \%$ (100 g/L). As concentrações de enzima investigadas variaram de 0 a $200 \mathrm{UI} / \mathrm{g}$ de pectina, divididos em 11 ensaios, sendo avaliada a concentração de CR.

\subsection{Micro-organismo e Preparo do Inóculo}

A cepa do micro-organismo Cupriavidus necator foi obtida junto ao Deutsche Sammlung von Mikroorganismen und Zellkulturen (DSMZ 545) e mantida na coleção de culturas do Departamento de Antibióticos/UFPE (UFPEDA 0604). Para a realização dos ensaios a cultura foi repicada em meio Agar nutriente e liofilizada em tubos de penicilina. Para o preparo do inóculo o conteúdo de cada tubo de penicilina foi transferido para um Erlenmeyer de $500 \mathrm{~mL}$ de capacidade contendo $200 \mathrm{~mL}$ de meio caldo nutriente (NB). O micro-organismo foi cultivado a $30{ }^{\circ} \mathrm{C}, 300 \mathrm{rpm}$, por 12 horas. Esse tempo de cultivo foi previamente estabelecido de forma a ser atingida a fase exponencial de crescimento. 


\subsection{Condições de Cultivo e Métodos Analíticos}

Com as condições de hidrólise definidas que favoreceram a obtenção de alta concentração de CR, foi realizado um cultivo em meio mineral de acordo com RAMSAY et al. (1990), modificado por ARAGÃO et al. (1996), tendo como únicas fontes de carbono o hidrolisado de pectina e um ensaio comparativo em meio formulado com glicose. Os ensaios, em triplicata, foram realizados em frascos Erlenmeyer de $500 \mathrm{~mL}$ contendo $200 \mathrm{~mL}$ de meio mineral (MM), sob agitação de $300 \mathrm{rpm}$, a $35^{\circ} \mathrm{C}$ por $24 \mathrm{~h}$, e concentração de inóculo de $10 \%$ (v/v). As condições de temperatura e concentração de inóculo foram baseadas no trabalho de Farias (2009), que utilizando essas condições obteve maior concentração celular e produção de PHA's.

Durante os cultivos foi realizado o acompanhamento da concentração de nitrogênio por meio de um kit colorimétrico (ALFAKIT ${ }^{\circledR}$ ), que emprega o método Brucina, onde os valores de absorbância (Abs) a $415 \mathrm{~nm}$ são convertidos em g/L de nitrogênio por meio de uma curva de calibração. No momento da restrição de nitrogênio a concentração de CR foi corrigida para $30 \mathrm{~g} / \mathrm{L}$, utilizando soluções concentradas de hidrolisado péctico $(70 \mathrm{~g} / \mathrm{L})$ e glicose $(300 \mathrm{~g} / \mathrm{L})$ nos seus respectivos cultivos. A medida de CR foi realizada pelo método do ácido 3,5 dinitrossalicílico (DNS) como descrito por MILLER (1959), utilizando glicose como referência para elaboração da curva de calibração. $\mathrm{O}$ pH foi monitorado por potenciômetro (Marconi®) e ajustado para 7,0 com KOH 5,0 M.

O crescimento celular foi avaliado por espectrofotometria a $600 \mathrm{~nm}$ (Marconi®), estando os valores de densidade óptica relacionados à massa seca por meio de uma curva de calibração. O acúmulo intracelular de PHA's foi verificado por análises qualitativas realizadas utilizando-se a técnica de coloração Sudan Black (SHEEHAN \& STOREY, 1947). Ao final do cultivo, a suspensão celular obtida foi centrifugada e submetida à extração com clorofórmio pelo método descrito por Ramsay et al. (1994), e o polímero obtido foi caracterizado por ressonância magnética nuclear (RMN) comparativamente a um padrão de P3HB.

\section{RESULTADOS E DISCUSSÕES}

\subsection{Planejamento experimental e performance enzimática}

Pelo planejamento fatorial de hidrólise enzimática obtivemos a superfície de resposta (Figura 1-A) para a variável resposta concentração de CR. Como podemos observar a região ótima para a concentração de CR foi atingida. Os valores críticos do modelo que maximizam a resposta foram equivalentes a uma concentração enzimática de 10,01 UI/g e agitação de 230,3 rpm. Pela análise estatística dos resultados obtivemos o gráfico de Pareto (Figura 1-B), onde todos os efeitos apresentaram-se significativos $(\mathrm{p}<0,05)$. A Equação 1 apresenta $o$ modelo codificado otimizado para a hidrólise enzimática de pectina após 24 h de biorreação.

$$
C R=-24,892+1,705 * x-0,067 * x^{2}+0,219 * y-0,00044 * y^{2}-0,00155 * x * y\left(R^{2}=0,8821\right)
$$

Teoricamente esperava-se que o aumento na agitação e na concentração de enzima promovesse um maior rendimento de hidrólise, mas isso não foi observado. Como 
trabalhamos com uma baixa concentração de substrato (1,0\%), uma alta taxa de agitação pode ter desfavorecido a formação do complexo enzima/substrato, prejudicando os rendimentos de hidrólise. Outros estudos demonstraram que com altas concentrações de substrato, maiores taxas de agitação favorecem o rendimento de hidrólise (LOCATELLI, 2012).
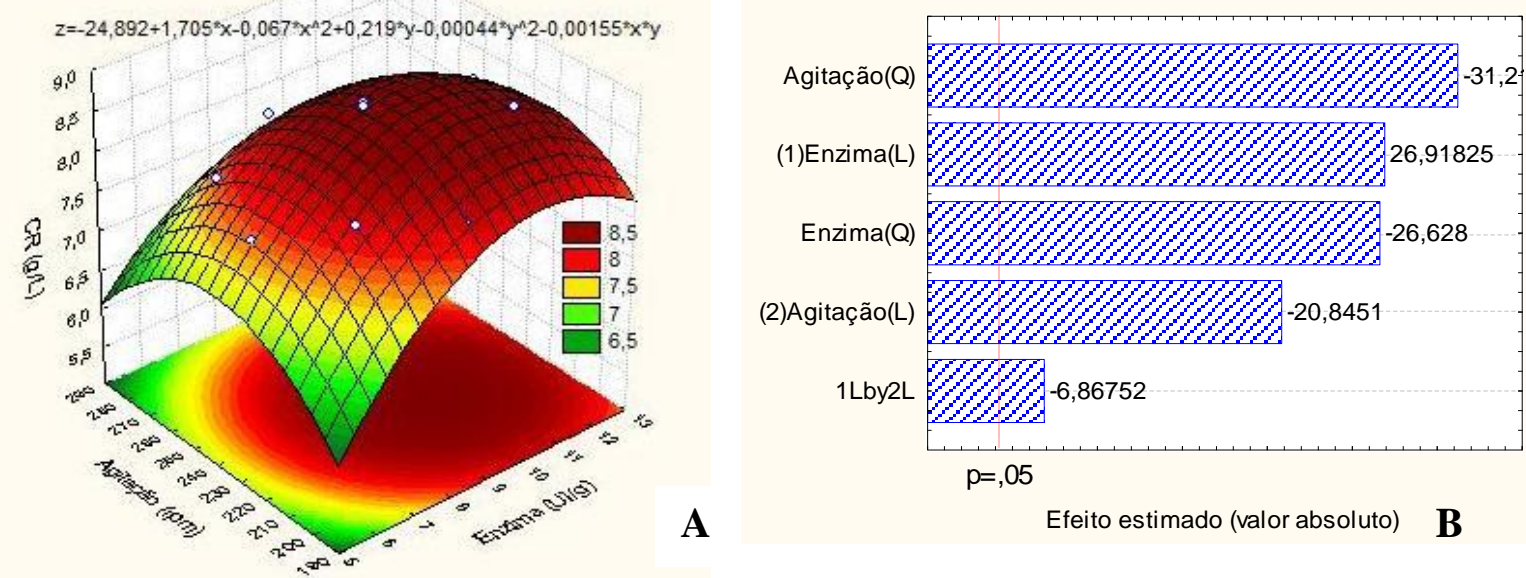

Figura 1 - Superfície de resposta (A) e gráfico de Pareto (B) para a concentração de CR em função da agitação e da concentração de enzima para o planejamento experimental em $24 \mathrm{~h}$ de hidrólise de pectina $1 \%(\mathrm{p} / \mathrm{v})$ com endo-poligalacturonase.

De modo geral, o aumento na concentração enzimática influencia o aumento da taxa de reação da enzima. Mas segundo Cavaco-Paulo (2011) esse aumento pode ser observado até o nível de saturação do substrato. A partir desse ponto, mesmo aumentando drasticamente a concentração da enzima, não ocorrem grandes incrementos nas taxas de biotransformação. Esse comportamento pode ser observado na Figura 2, onde temos o gráfico da performance enzimática. A concentração de $\mathrm{CR}$ aumenta da forma acentuada com o aumento da concentração enzimática até $10 \mathrm{UI} / g$ de pectina, onde é possível se obter em média $68,8 \pm 0,5$ $\mathrm{g} / \mathrm{L}$ de CR. A partir desse ponto, mesmo aumentando drasticamente a concentração de enzima até $200 \mathrm{UI} / \mathrm{g}$, o rendimento de hidrólise não aumenta significativamente.

Resultado semelhante foi observado por Rodríguez-Nogales et al. (2007), que trabalhando com endopectinase através do método de planejamento experimental, verificou que a taxa de reação não aumenta linearmente com o incremento na concentração da enzima. Esse comportamento também pode ser observado para outras enzimas. Como demonstrado por Michizoe et al. (2001), que estudaram o efeito da concentração de lacase (0 a $15 \mu \mathrm{M})$ sobre a degradação de $o$-clorofenol, foi verificado que a partir de $11 \mu \mathrm{M}$ o rendimento da degradação foi praticamente estável. 


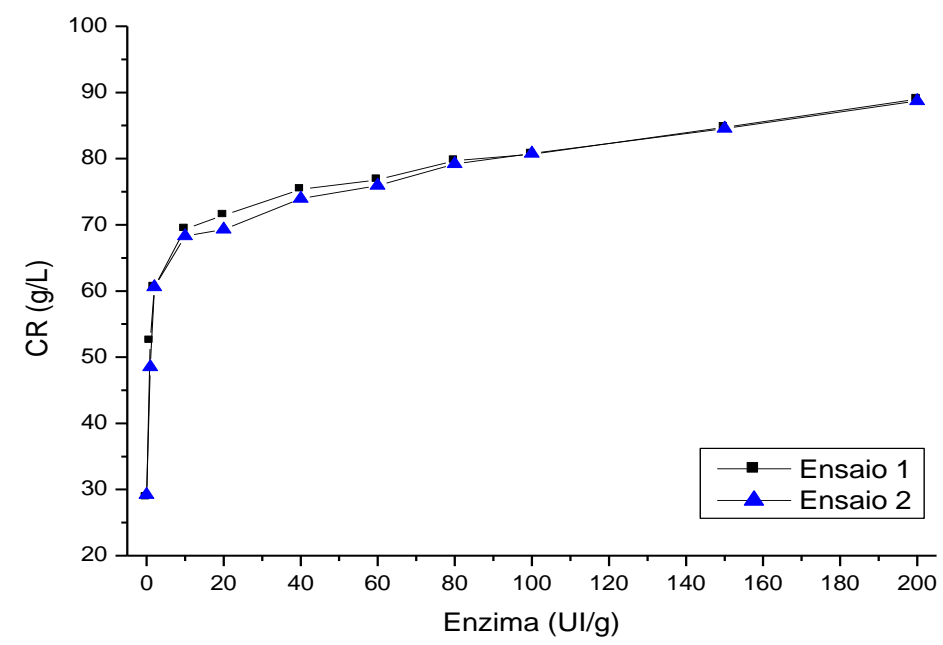

Figura 2 - Gráfico de performance enzimática de endo-poligalacturonase durante a hidrólise de pectina $(10 \% \mathrm{p} / \mathrm{v})$ durante $24 \mathrm{~h}$.

A concentração enzimática de $10 \mathrm{UI} / g$ de pectina representa a menor relação enzima/substrato com rendimento significativo de hidrólise, e esse valor está em concordância com o planejamento fatorial de hidrólise enzimática empregando $1 \%(\mathrm{p} / \mathrm{v})$ de substrato. A partir deste resultado, foi definido em $10 \mathrm{UI} / \mathrm{g}$ de pectina o parâmetro de concentração enzimática considerado ótimo para os ensaios de hidrólise empregando-se agora $10 \%(\mathrm{p} / \mathrm{v}) \mathrm{de}$ substrato e agitação de $300 \mathrm{rpm}$. Um ensaio em triplicata foi realizado nessas condições para confirmação desse resultado, obtendo-se 71,5 \pm 0,8 g/L de CR.

\subsection{Produção de PHA's - Hidrolisado de Pectina e Padrão Glicose}

Com o hidrolisado obtido nas condições estabelecidas foi realizado um cultivo em meio formulado com o hidrolisado de pectina e um comparativo, em meio formulado com glicose, visando à produção de PHA's. As fases de crescimento celular e produção de PHA's foram acompanhadas por um período de 42 horas. $\mathrm{O}$ pH foi monitorado em intervalos de 1 hora e controlado em 7,0 \pm 0,5, com a adição de $\mathrm{KOH}$ sob condições de esterilidade. Os demais parâmetros monitorados estão apresentados na Figura 3-A (ensaio com glicose) e Figura 3-B (ensaio com hidrolisado de pectina).

Para o cultivo com glicose a fase exponencial de crescimento celular inicia-se 2 horas após a inoculação até 10 horas de cultivo, momento em que ocorre a limitação de nitrogênio. $\mathrm{O}$ cultivo com hidrolisado de pectina apresenta uma fase lag de aproximadamente 4 horas, quando se inicia a fase de crescimento exponencial que vai até 14 horas de cultivo, momento em que ocorre a limitação total de nitrogênio. Esta fase está relacionada principalmente ao aumento da biomassa celular, apesar de ocorrer um pequeno acúmulo de biopolímero (FARIAS, 2009). Como pode ser observado nas curvas de crescimento, para ambos os cultivos, a biomassa continua aumentando após a fase de limitação de nitrogênio, mas não de forma exponencial, o que está relacionado principalmente ao acúmulo intracelular de biopolímeros. 

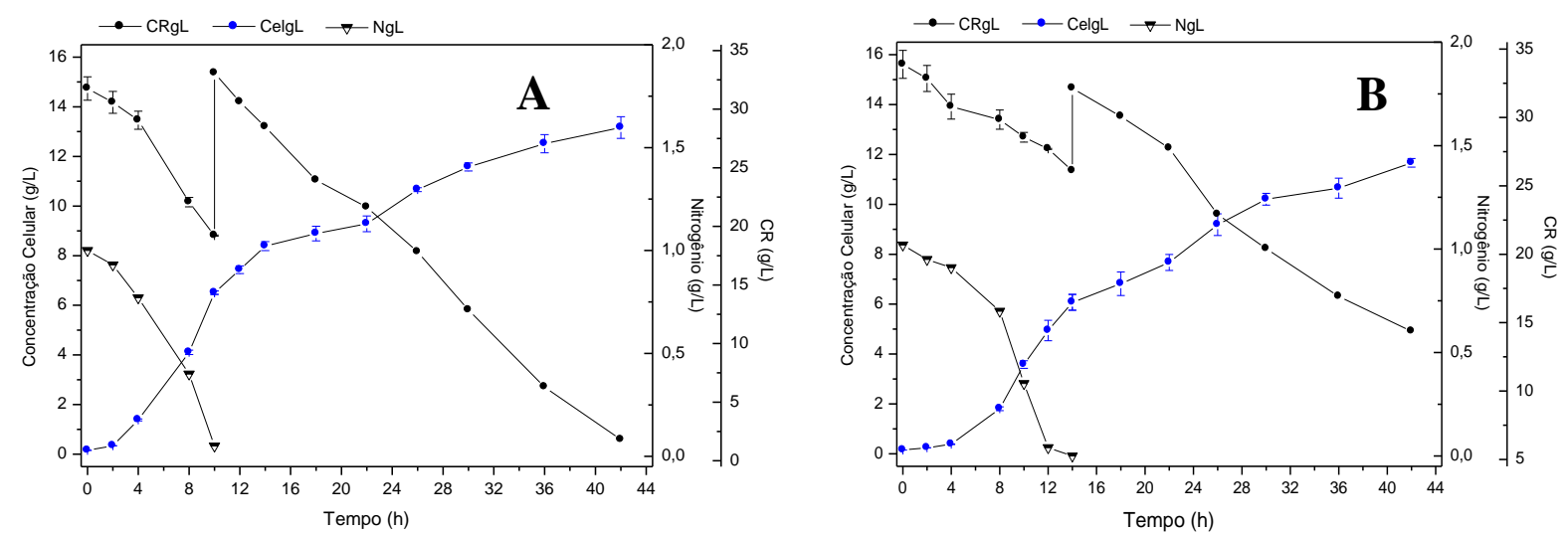

Figura 3 - Valores de crescimento celular, consumo de CR e nitrogênio durante o cultivo de C. necator em meio mineral formulado com glicose (A) e hidrolisado enzimático de pectina (B) como fonte de carbono.

Os meios para os cultivos com glicose foram formulados com uma concentração média inicial de CR de 31,8 g/L, que decresce até 19,2 g/L no momento da limitação, apresentando um consumo médio de $12,6 \mathrm{~g} / \mathrm{L}$ de CR. Nessa fase, a curva de crescimento celular indica uma concentração de $6,5 \mathrm{~g} / \mathrm{L}$ de células. Desconsiderando a concentração inicial de células $(0,16 \mathrm{~g} / \mathrm{L})$ temos uma taxa de conversão de substrato em células $\left(\mathrm{Y}_{\mathrm{X} / \mathrm{S}}\right) \mathrm{de}$ $0,50 \mathrm{~g}_{\text {cél }} / \mathrm{g}_{\text {subs. }}$ Para o cultivo com hidrolisado de pectina a concentração média inicial de CR foi de $33,9 \mathrm{~g} / \mathrm{L}$, decrescendo até $26,1 \mathrm{~g} / \mathrm{L}$ no momento da limitação, com um consumo médio de 7,8 g/L de CR e uma concentração celular de 6,1 g/L. Desconsiderando a concentração inicial de células $(0,15 \mathrm{~g} / \mathrm{L})$, temos um $\mathrm{Y}_{\mathrm{X} / \mathrm{S}}$ de $0,76 \mathrm{~g}_{\text {cé́l }} / \mathrm{g}_{\text {subs }}$.

O $\mathrm{Y}_{\mathrm{X} / \mathrm{S}}$ obtido para o cultivo com glicose está de acordo com o valor teórico $(0,5$ $\mathrm{g}_{\text {cél }} / \mathrm{g}_{\text {subs }}$ ) sugerido para $C$. necator (REPASKE \& REPASKE, 1976), e pode ser comparado aos valores obtidos por Farias (2009), que trabalhando com melaço cítrico obteve 0,52 e 0,48 $\mathrm{g}_{\text {cél }} / \mathrm{g}_{\text {subs. }}$ Já o $\mathrm{Y}_{\mathrm{X} / \mathrm{S}}$ obtido para o cultivo com hidrolisado de pectina está acima dos valores encontrados na literatura, sendo próximo aos valores obtidos em cultivos usando óleos vegetais como fonte de carbono. Ao final dos cultivos as concentrações residuais de CR foram de 1,80 e 14,4 $\mathrm{g} / \mathrm{L}$ para os cultivos com glicose e hidrolisado de pectina, respectivamente. Valores residuais da fonte de carbono são esperados e também observados em outros trabalhos (BAEI et al., 2009), mas em nosso estudo essa concentração residual pode estar relacionada à presença de oligômeros devido à atividade endoPG da enzima utilizada.

Através da coloração das células pela metodologia Sudan Black, foi possível verificar a presença intracelular de PHA's em ambos os cultivos, e considerando o consumo quase total dos CR no meio com glicose, os cultivos foram finalizados simultaneamente. Com o material celular obtido ao final do cultivo de 42 horas, foi realizada a extração dos PHA's e a caracterização pela técnica de ressonância magnética nuclear (RMN), indicando que os PHA's obtidos em ambos os cultivos foi o P-3HB. 
Concluímos que os hidrolisados pécticos podem ser um potencial substituto da glicose utilizada como fonte de carbono em processos industriais de cultivo para obtenção de PHB. Sendo um substrato disponível em grandes quantidades como subproduto das indústrias de extração de sucos, podem vir a ser uma alternativa de baixo custo para esse processo.

\section{REFERÊNCIAS}

ARAGÃO, G.M.F.; LINDLEY, N.D.; URIBELARREA, J.L.; PAREILLEUX, A. Maintaining a controlled residual growth capacity increases the production of polyhydroxyalkanoate copolymers by A. eutrophus. Biotech. Let., v.18, p.937-942, 1996.

BAEI, M.S.; NAJAFPOUR, G.D.; YOUNESI, H.; TABANDEH, F.; EISAZADEH, H. Poly(3-hydroxybutyrate) synthesis by Cupriavidus necator DSMZ 545 utilizing various carbon sources. W. Appl. Sc. J., v.7, p.157-161, 2009.

CAVACO-PAULO, Artur. Minicurso: Estabilização de Enzimas para Aplicação Industrial. UNICAP - Universidade Católica de Pernambuco, setembro de 2011.

FARIAS, D. Produção e caracterização de poli(3-hidroxibutirato-co-3-hidroxivalerato) por Cupriavidus necator em melaço cítrico. Dissertação de Mestrado, Universidade Federal de Santa Catarina, Florianópolis, 2009, 197p.

LOCATELLI, G.O.; SILVA, G.D.; FINKLER, L.; FINKLER, C.L.L. Acid hydrolysis of pectin for cell growth of Cupriavidus necator. Biotechnol., v.1, p.1-8, 2011.

LOCATELLI, G.O. Estudo das condições de hidrólise da pectina para uso como substrato na produção de polihidroxialcanoatos. Dissertação de mestrado, Universidade Federal de Pernambuco, Recife, 2012, 119p.

MAY, C.D. Pectins. Em: PHILLIPS, G.O.; WILLIAMS, P.A. (eds). Handbook of hydrocolloids, $1^{\circ}$ Edição, CRC Press LLC, New York, p.169-188, 2000.

MICHIZOE, J.; GOTO, M.; FURUSAKI, S. Catalytic activity of laccase hosted in reversed micelles. J. Biosc. Bioeng., v.92, n.1, p.67-71, 2001.

MILLER, G.L. Use of dinitrosalicylic acid reagent for determination of reducing sugar. Analyt. Chem., v.31, p.426-428, 1959.

POIRIER, Y.; NAWRATH, C.; SOMERVILLE, C. Production of polyhydroxyalkanoates, a family of biodegradable plastic and elastomers, in bacteria and plants. Nat. Biotech., v.13, p.142-150, 1995.

RAMSAY, B.A.; LOMALIZA, K.; CHAVARIE, C.; DUBE, B.; BATAILLE, P.; RAMSAY, J.A. Production of poly-( $\beta$-hydroxybutyric-co- $\beta$-hydroxyvaleric) acids. Appl. Environ. Microbiol., v.56, p.2093-2098, 1990.

RAMSAY, J.A.; BERGER, E., VOYER, R., CHAVARIE, C., RAMSAY, B.A. Extraction of poly-3-hydroxybutyrate using chlorinated solvents. Biotechnology Techniques. v.8, p.589-594, 1994.

REPASKE, R.; REPASKE, A.C. Quantitative requirements for exponential growth of Alcaligenes eutrophus. Appl. Environ. Microbiol., v.32, p.585-591, 1976.

SHEEHAN H.L; STOREY, G.W. An improved method of staining leukocyte granules with Sudan Black. B. J Pathol Bacteriol, v.59, p336, 1947.

YAPO, B.N.; ROBERT, C.; ETIENNE, I.; WATHELET, B.; PAQUOT, M. Effect of extraction conditions on the yield, purity and surface properties of sugar beet pulp pectin extracts. Food Chem., v.100, p.1356-1364, 2006. 